\title{
PENGARUH PEMBERIAN LATIHAN ABDOMINAL STRETCHING TERHADAP TINGKAT NYERI HAID (DYSMENORRHOEA) PADA SISWI KELAS X DAN XII SMKN 3 MALANG
}

\author{
Vidia Ariska Putri \\ Fakultas Ilmu Keolahragaan \\ Universitas Negeri Malang \\ J1. Semarang 5 Malang, 65145, Indonesia \\ vidiaariska@yahoo.com \\ Desiana Merawati \\ Fakultas Ilmu Keolahragaan \\ Universitas Negeri Malang \\ J1. Semarang 5 Malang, 65145, Indonesia \\ Olivia Andiana \\ Fakultas Ilmu Keolahragaan \\ Universitas Negeri Malang \\ J1. Semarang 5 Malang, 65145, Indonesia
}

\begin{abstract}
ABSTRAK
Wanita dikatakan sudah aqil baliq jika sudah mengalami fase menstruasi, secara periodik setiap bulan wanita normal akan mengalami siklus reproduksi, yaitu menstruasi atau meluruhnya jaringan endometrium karena tidak adanya telur matang yang dibuahi oleh sperma (Cahyaningtias \& Wahyuliati, 2007:121). Siklus mensturasi pada wanita normalnya berkisar antara 21-32 hari. Namun, yang sering terjadi tidak semua wanita yang mengalami menstruasi merasakan nyaman karena adanya gangguan yang biasanya muncul antara lain bau, suasana hati yang menjadi sering bad mood, bahkan rasa nyeri yang disebut $d y s-$ menorrhoea. Tujuan penelitian ini untuk mengetahui pengaruh latihan abdominal stretching terhadap nyeri haid (dysmenorrhoea)pada siswi SMKN 3 Malang. Metode penelitian ini adalah one group pretest posttest design yaitu rancangan eksperimen semu tanpa menggunakan kelompok pembanding. Pada awal penelitian dilakukan observasi awal (pretest) yang dijadikan sebagai dasar untuk membandingkan perubahan-perubahan yang terjadi setelah adanya eksperimen (perlakuan). Data diuji menggunakan analisis regresi linier yang diolah menggunakan aplikasi minitab16. Hasil penelitian setelah pemberian perlakuan selama 3 bulan (1 minggu 3 kali) 36 kali dapat dikatakan bahwa dengan melakukan senam abdominal stretching dapat menurunkan nyeri. Hasil analisis regresi linier dengan taraf signifikasi 0.050 adalah $0.000<\alpha=0.05$ maka dapat disimpulkan bahwa latihan abdominal stretching dapat memberikan pengaruh yang signifikan terhadap penurunan tingkat nyeri haid (dysmenorrhoea) pada subyek penelitian yaitu 117 siswi SMKN 3 Malang yang mengalami nyeri haid (dysmenorrhoea).
\end{abstract}

Kata Kunci: Dysmenorrhoea, Abdominal Stretching Exercise.

Wanita dikatakan sudah aqil baliq jika sudah mengalami fase menstruasi, secara periodik setiap bulan wanita normal akan mengalami siklus reproduksi, yaitu menstruasi atau "meluruhnya jaringan endometrium karena tidak adanya telur matang yang dibuahi oleh sperma" (Cahyaningtias \& Wahyuliati, 2007:121). Menurut Fajaryanti (2011:9) "menstruasi atau haid atau datang bulan adalah 
perubahan fisiologis dalam wanita yang terjadi secara berkala dan dipengaruhi oleh hormon reproduksi yang terjadi selama 3-7 hari". Menurut Tuduho dkk (2014:2) "panjang siklus mensturasi adalah jarak antara tanggal mulainya mensturasi yang lalu dan mulainya mensturasi berikutnya. Siklus mensturasi pada wanita normalnya berkisar antara 21-32 hari". Namun, yang sering terjadi tidak semua wanita yang mengalami menstruasi merasakan nyaman karena adanya gangguan yang biasanya muncul antara lain bau, suasana hati yang menjadi sering bad mood, bahkan rasa nyeri yang disebut dismenorrhoea.

Nyeri haid atau dismenorrhoea merupakan "rasa nyeri yang terjadi sebelum atau selama menstruasi yang sangat menyiksa bagi wanita dan hal yang tidak pernah diinginkan oleh wanita" (Windastiwi dkk, 2017:2). Nyeri haid (dysmenorrhoea) pada saat menstruasi tentu saja sangat menyiksa seperti sakit menusuk, "nyeri yang hebat di sekitar bagian bawah dan bahkan kadang mengalami kesulitas berjalan, merasakan mual atau bahkan hingga muntah, dan ada yang hingga menimbulkan emosional yg tinggi atau bahkan hingga melakukan perilaku yang buruk" (Unsal dkk, 2010:139). "Angka kejadian dismenorrhoea di dunia sangat besar, ratarata lebih besar dari 50\%. Di Amerika angka presentasenya sekitar $60 \%$ dan 10$15 \%$, di Swedia sekitar $72 \%$, dan di Indonesia sekitar 54,89\%" (Fajaryati, 2011:2). Latihan abdominal stretching merupakan suatu latihan peregangan otot terutama pada perut yang dilakukan selama 10 menit yang "bermanfaat untuk meningkatkan kekuatan otot, daya tahan, dan fleksibilitas karena dengan gerakan tersebut dapat merilekskan ketegangan otot sehingga dapat mengurangi nyeri (dismenorrhoea)" (Salbiah, 2014:74).

Pada berbagai penelitian juga dikatakan bahwa dengan latihan yang secara baik dan teratur dapat mengurangi rasa nyeri, berdasarkan hal tersebut peneliti akan memberikan latihan abdominal stretching terhadap nyeri haid (dysmenorrhoea) yang dialami siswi SMKN 3 Malang sebanyak 117 siwi mengalami nyeri haid (dysmenorrhoea) dengan skala nyeri ringaan sebanyak 35 siswi, nyeri sedang 72 siswi, nyeri berat 10 siswi. Dengan tingkatan nyeri mild sebanyak 12 siswi, uncomfortable sebanyak 23 siswi, moderate sebanyak 44 siswi, distracting sebanyak 23 siswi, distressing sebanyak 5 siswi, unmanageable sebanyak 6 siswi, intense sebanyak 2 siswi, severe sebanyak 1 siswi, dan unable to move sebanyak 1 siswi.

\section{METODE}

Metode penelitian ini adalah one group pretest posttest design yaitu rancangan eksperimen semu tanpa menggunakan kelompok pembanding. Pada awal penelitian dilakukan observasi awal (pretest) yang dijadikan sebagai dasar untuk membandingkan perubahanperubahan yang terjadi setelah adanya eksperimen (perlakuan). Data diuji menggunakan analisis regresi linier yang diolah menggunakan aplikasi minitab16.

Peneliti akan memberikan latihan abdominal stretching terhadap nyeri haid (dysmenorrhoea) yang dialami siswi SMKN 3 Malang sebanyak 117 siwi mengalami nyeri haid (dysmenorrhoea) dengan skala nyeri ringaan sebanyak 35 siswi, nyeri sedang 72 siswi, nyeri berat 10 siswi. Dengan tingkatan nyeri mild sebanyak 12 siswi, uncomfortable sebanyak 23 siswi, moderate sebanyak 44 siswi, distracting sebanyak 23 siswi, distressing sebanyak 5 siswi, unmanageable sebanyak 6 siswi, intense sebanyak 2 siswi, severe sebanyak 1 siswi, dan unable to move sebanyak 1 siswi.

Program latihan yang diberikan selama 3 bulan atau 12 minggu (1 minggu 3 kali), 
HASIL

Berdasarkan hasil penelitian adanya perubahan berat badan dan tinggi badan dimulai setelah $24 \mathrm{X}$ perlakuan atau 8 minggu yang disajikan pada tabel 4.1 berikut ini:

Tabel 4.1 Indeks Massa Tubuh

\begin{tabular}{|c|c|c|c|c|c|}
\hline $\begin{array}{c}\text { Angk } \\
\text { a }\end{array}$ & $\begin{array}{c}\text { Kate } \\
\text { gori }\end{array}$ & $\begin{array}{c}\text { Pret } \\
\text { est }\end{array}$ & $\begin{array}{l}\text { Data } \\
\text { I }\end{array}$ & $\begin{array}{c}\text { Data } \\
\text { II }\end{array}$ & $\begin{array}{c}\text { Data } \\
\text { III }\end{array}$ \\
\hline$<17$ & $\begin{array}{c}\text { Sanga } \\
\mathrm{t} \\
\text { buruk }\end{array}$ & 0 & 0 & 0 & 0 \\
\hline $\begin{array}{c}17,1 \\
- \\
18,4\end{array}$ & $\begin{array}{c}\text { Buru } \\
\mathrm{k}\end{array}$ & 0 & 0 & 0 & 0 \\
\hline $\begin{array}{c}18,5 \\
- \\
24,9\end{array}$ & $\begin{array}{c}\text { Norm } \\
\text { al }\end{array}$ & 12 & 12 & 12 & 12 \\
\hline $\begin{array}{c}25- \\
27\end{array}$ & Lebih & 48 & 48 & 45 & 39 \\
\hline$>27$ & $\begin{array}{c}\text { Sanga } \\
t \\
\text { lebih }\end{array}$ & 57 & 57 & 60 & 66 \\
\hline & Total & 117 & 117 & 117 & 117 \\
\hline
\end{tabular}

\section{Skala Nyeri}

Berdasarkan hasil penelitian adanya perubahan skala nyeri pada subyek dapat dilihat pada tabel 4.2, 4.3, 4.4, dan 4.5 berikut ini:

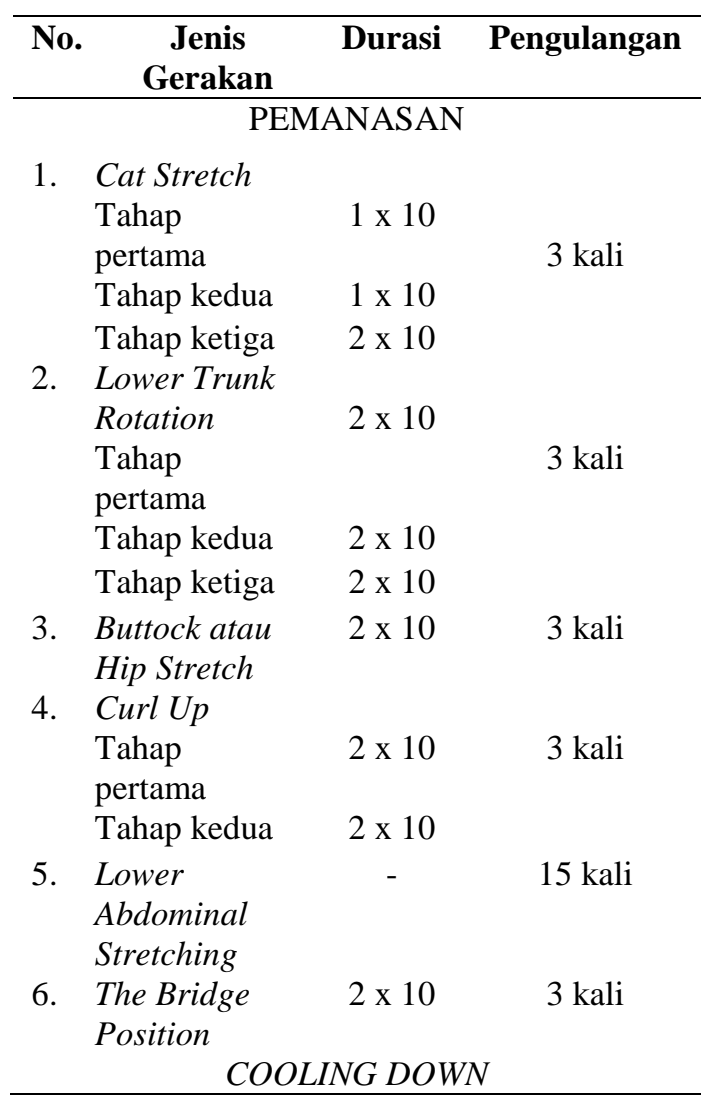

Tabel 4.2 Skala Nyeri Sebelum Perlakuan

\begin{tabular}{cccc}
\hline $\begin{array}{c}\text { Skala } \\
\text { Nyeri }\end{array}$ & Tingkatan & Frekuensi & $\%$ \\
\hline Ringan & $1-3$ & 35 & $30 \%$ \\
Sedang & $4-6$ & 72 & $62 \%$ \\
Berat & $7-10$ & 10 & $8 \%$ \\
Total & & 117 & $100 \%$ \\
\hline
\end{tabular}

Tabel 4.3 Skala Nyeri Setelah 12x Pertama (Bulan Agustus)

\begin{tabular}{cccc}
\hline $\begin{array}{c}\text { Skala } \\
\text { Nyeri }\end{array}$ & Tingkatan & Frekuensi & $\%$ \\
\hline Ringan & $1-3$ & 72 & $62 \%$ \\
Sedang & $4-6$ & 41 & $35 \%$ \\
Berat & $7-10$ & 4 & $3 \%$ \\
Total & & 117 & 100 \\
& & & $\%$ \\
\hline
\end{tabular}

Tabel 4.4 Skala Nyeri Setelah 12x Kedua (Bulan September)

\begin{tabular}{lccc}
\hline $\begin{array}{l}\text { Skala } \\
\text { Nyeri }\end{array}$ & Tingkatan & Frekuensi & $\%$ \\
\hline None & 0 & 12 & $10 \%$ \\
Ringan & $1-3$ & 78 & $67 \%$ \\
Sedang & $4-6$ & 23 & $20 \%$ \\
Berat & $7-10$ & 4 & $3 \%$ \\
Total & & 117 & 100 \\
\hline
\end{tabular}

Tabel 4.5 Skala Nyeri Setelah 12x Ketiga (Bulan Oktober)

\begin{tabular}{lccc}
\hline $\begin{array}{c}\text { Skala } \\
\text { Nyeri }\end{array}$ & Tingkatan & Frekuensi & $\%$ \\
\hline None & 0 & 40 & $34 \%$ \\
Ringan & $1-3$ & 64 & $55 \%$ \\
Sedang & $4-6$ & 12 & $10 \%$ \\
Berat & $7-10$ & 1 & $1 \%$ \\
& Total & 117 & $100 \%$ \\
\hline
\end{tabular}

\section{Tingkatan Nyeri Haid}

Berdasarkan hasil penelitian adanya perubahan tingkatan nyeri pada subyek dapat dilihat pada tabel 4.6, 4.7, 4.8, dan 4.9 berikut ini:

Tabel 4.6 Tingkatan Nyeri Sebelum Perlakuan dan Frekuensinya

\begin{tabular}{cccc}
$\begin{array}{c}\text { Tingkatan } \\
\text { Nyeri }\end{array}$ & Keterangan & $\begin{array}{c}\text { Jumlah } \\
\text { Subyek }\end{array}$ & $\%$ \\
\hline 1 & Minimal pain & - & $0 \%$ \\
2 & Mild & 12 & $10 \%$ \\
3 & Uncomfortable & 23 & $20 \%$ \\
\hline
\end{tabular}




\begin{tabular}{cccc}
\hline 4 & Moderate & 44 & $37 \%$ \\
5 & Distracting & 23 & $20 \%$ \\
6 & Distressing & 5 & $4 \%$ \\
7 & Unmanageable & 6 & $5 \%$ \\
8 & Intense & 2 & $2 \%$ \\
9 & Severe & 1 & $1 \%$ \\
10 & Unable to & 1 & $1 \%$ \\
& move & 117 & $100 \%$ \\
\hline
\end{tabular}

Tabel 4.7 Tingkatan Nyeri Setelah 12x Pertama (Bulan Agustus) dan Frekuensinya

\begin{tabular}{|c|c|c|c|}
\hline $\begin{array}{c}\text { Tingkatan } \\
\text { Nyeri }\end{array}$ & Keterangan & $\begin{array}{l}\text { Jumlah } \\
\text { Subyek }\end{array}$ & $\%$ \\
\hline 1 & Minimal pain & 7 & $6 \%$ \\
\hline 2 & Mild & 30 & $26 \%$ \\
\hline 3 & Uncomfortable & 35 & $30 \%$ \\
\hline 4 & Moderate & 24 & $20 \%$ \\
\hline 5 & Distracting & 12 & $10 \%$ \\
\hline 6 & Distressing & 5 & $4 \%$ \\
\hline 7 & Unmanageable & 2 & $2 \%$ \\
\hline 8 & Intense & 2 & $2 \%$ \\
\hline 9 & Severe & 0 & $0 \%$ \\
\hline \multirow[t]{2}{*}{10} & $\begin{array}{c}\text { Unable to } \\
\text { move }\end{array}$ & 0 & $0 \%$ \\
\hline & Cotal & 117 & $100 \%$ \\
\hline
\end{tabular}

Tabel 4.8 Tingkatan Nyeri Setelah 12x Kedua (Bulan September) dan Frekuensinya

\begin{tabular}{|c|c|c|c|}
\hline $\begin{array}{c}\text { Tingkatan } \\
\text { Nyeri }\end{array}$ & Keterangan & $\begin{array}{l}\text { Jumlah } \\
\text { Subyek }\end{array}$ & $\%$ \\
\hline 0 & None & 12 & $10 \%$ \\
\hline 1 & Minimal pain & 26 & $22 \%$ \\
\hline 2 & Mild & 34 & $29 \%$ \\
\hline 3 & Uncomfortable & 18 & $15 \%$ \\
\hline 4 & Moderate & 15 & $13 \%$ \\
\hline 5 & Distracting & 6 & $5 \%$ \\
\hline 6 & Distressing & 2 & $2 \%$ \\
\hline 7 & Unmanageable & 4 & $4 \%$ \\
\hline 8 & Intense & 0 & $0 \%$ \\
\hline 9 & Severe & 0 & $0 \%$ \\
\hline \multirow[t]{2}{*}{10} & $\begin{array}{c}\text { Unable to } \\
\text { move }\end{array}$ & 0 & $0 \%$ \\
\hline & Cotal & 117 & $100 \%$ \\
\hline
\end{tabular}

Tabel 4.9 Tingkatan Nyeri Setelah 12x Ketiga (Bulan Oktober) dan Frekuensinya

\begin{tabular}{cccc}
\hline $\begin{array}{c}\text { Tingkatan } \\
\text { Nyeri }\end{array}$ & Keterangan & $\begin{array}{c}\text { Jumlah } \\
\text { Subyek }\end{array}$ & $\%$ \\
\hline 0 & None & 40 & $34 \%$ \\
1 & Minimal pain & 32 & $27 \%$ \\
\hline
\end{tabular}

\begin{tabular}{cccc}
\hline 2 & Mild & 19 & $16 \%$ \\
3 & Uncomfortable & 13 & $11 \%$ \\
4 & Moderate & 9 & $8 \%$ \\
5 & Distracting & 3 & $3 \%$ \\
6 & Distressing & 0 & $0 \%$ \\
7 & Unmanageable & 1 & $1 \%$ \\
8 & Intense & 0 & $0 \%$ \\
9 & Severe & 0 & $0 \%$ \\
10 & Unable to & 0 & $0 \%$ \\
& move & 117 & $100 \%$ \\
\hline & Total & & \\
\hline
\end{tabular}

\section{Hasil Analisis Statistik}

Hasil analisis statistik dapat dilihat pada tabel 4.10 dibawah ini:

\begin{tabular}{cccc}
\multicolumn{4}{c}{ Tabel 4.10 Hasil Analisis Statistik } \\
\hline & I & II & III \\
\hline P & 0.040 & 0.046 & 0.096 \\
F & 124.57 & 68.80 & 51.69 \\
SD & 0.8087 & 1.121 & 1.073 \\
N & 117 & 117 & 117 \\
\hline
\end{tabular}

Keterangan: $\mathrm{P}=P$-value atau ukuran probabilitas

$\mathrm{F}=$ F-hitung

$\mathrm{SD}=$ Standart Deviasi

$\mathrm{N}=$ Jumlah responden perbulan

I = Data bulan Agustus

II = Data bulan September

III = Data bulan Oktober

\section{PEMBAHASAN}

Indeks Massa Tubuh

Kategori indeks massa tubuh sebelum perlakuan yaitu kategori normal 12 siswi, lebih 48 siswi, dan sangat lebih atau obesitas yaitu 57 siswi yang kemudian di bulan September mengalami perubahan dengan kategori normal 12 siswi, lebih 45 siswi, sangat lebih atau obesitas 60 siswi. Perubahan indeks massa tubuh juga terjadi di akhir penelitian yaitu menjadi kategori normal 12 siswi, lebih 39 siswi, sangat lebih atau obesitas 66 siswi. Dengan rincian kategori indeks massa tubuh yang meningkat dikarenakan pola makan yang tidak teratur maka 
menyebabkan peningkatan kategori obesitas di setiap bulannya, obesitas dipengaruhi oleh pola makan dari siswi tersebut.

\section{Penurunan Tingkat Nyeri}

Setelah 36 kali, kemudian penurunan tingkat nyeri pada bulan Oktober dengan rincian tingkat nyeri none atau tidak ada nyeri 40 subyek (34\%), nomor 1 sebanyak 32 subyek (27\%), tingkat 2 sebanyak 19 subyek (16\%), tingkat 3 sebanyak 13 subyek (11\%), tingkat 4 sebanyak 9 subyek (8\%), tingkat 5 sebanyak 3 subyek (3\%), tingkat 6 sebanyak 0 subyek (0\%), tingkat 7 sebanyak 1 subyek (1\%), tingkat 8 sebanyak 0 subyek (0\%), tingkat 9 sebanyak 0 subyek (0\%), tingkat 10 sebanyak 1 subyek $(0 \%)$.

\section{KESIMPULAN}

Berdasarkan hasil penelitian tentang "Pengaruh Pemberian Latihan Abdominal Stretching terhadap Tingkat Nyeri Haid (dysmenorrhoea) pada Siswi Kelas X dan XII SMKN 3 Malang" dapat disimpulkan sebagai berikut: Bahwa setelah pemberian perlakuan selama 3 bulan (1 minggu 3 kali) 36 kali dapat dikatakan bahwa dengan melakukan latihan abdominal stretching dapat menurunkan nyeri. Hasil analisis regresi linier dengan taraf signifikasi 0.050 adalah $0.000<\alpha=0.05$ maka dapat disimpulkan bahwa latihan abdominal stretching dapat memberikan pengaruh yang signifikan terhadap penurunan tingkat nyeri haid (dysmenorrhoea) pada subyek penelitian yaitu 117 siswi SMKN 3 Malang yang mengalami nyeri haid (dysmenorrhoea).

\section{SARAN}

Berdasarkan kesimpulan di atas, maka selanjutnya peneliti mengembangkan beberapa saran. Adapun saran tersebut adalah sebagai berikut: 1) Perlu diadakannya pengetahuan lebih mendalam agar mulai berkurangnya rasa nyeri pada remaja. 2) Perlu diadakannya penelitian yang serupa agar lebih banyak lagi referensi yang mudah didapatkan.

\section{REFERENSI}

Anas, S.H. 2010. Sketsa Kesehatan Reproduksi Remaja. Jurnal Studi Gender dan Anak. 5(1). 199-214.

Arief, Amel Fouad., Kamal, Asmaca., Ali, Saher Ahmed. 2017. Effect of Smoking Passive on Dysmenorrhea Among Secondary School Student : Instructions Guideline. Journal of Nursey and Health Science (IOSR-JHNS). 6(5). 13-21.

Begum, Monawara., Dash, Sumit., Sharma, H.K. 2016. Menstrual Disorders : Causes and Natural Remedies. Journal of Pharmaceutical, Chemical, And Biological. 4(2). 307-320.

Bhattarai, Sabina., Subedi, Sudarshan., Acharya, Shiva Raj. 2018. Factors Associated With Early Menarche Among

Adolescents Girls: A Study From Nepal. Sm Journal Of Community Medicine. 4(1). 1-11.

Cahyaningtias, P.L., Wahyuliati, T. 2007. Pengaruh Olahraga terhadap Derajat Nyeri Dismenorhea pada Wanita Belum Menikah. Jurnal Mutiara Medika. 7(2). 120-126.

Chaidar, Warianto. 2011. Daur menstruasi. Jurnal Kesehatan Andalas. 5(3). 522-527.

Deoray, Viska \& Page, Amit. 2018. Treatment of Menstrual Disorders : A Shift From Syntetic Drugs to Drugs of Natural Origin. Journal of Pharma and Bioscience. 9(1). 120-131. 
Ermawati, E., Indriyati, E.P. 2011. Hubungan antara Konsep Diri Dengan Perilaku Konsumtif pada Remaja di Smpn 1 Piyungan. Jurnal Spirits. 2(1). $1-12$.

Ernawati, Indriyati. 2017. Pengaruh Latihan Peregangan Abdominal terhadap Penurunan Nyeri Haid (Dysmenorrhoea) Mahasiswi STIKES Tanawali Persada Takalar. Skripsi Diterbitkan. Sulawesi Selatan: Fakultas Kesehatan Masyarakat Universitas Hassanudin. 7(4). 368-373.

Fajaryanti, N. 2011. Hubungan Kebiasaan Olahraga dengan Dismenorhea Primer Remaja Putri di SMPN 2 Mirit Kebumen. Skripsi Diterbitkan. Jawa Tengah: Fakultas Ilmu Kesehatan Sekolah Tinggi Ilmu Kesehatan Muhammadiyah Gombong. 1-12.

Fauziah, M.N. 2015. Pengaruh Latihan Abdominal Stretching terhadap Intensitas Nyeri Haid (Dysmenorrhoea) pada Remaja Putri di SMK AL FURQON Bantarkawung Kabupaten Brebes. Skripsi Diterbitkan. Jakarta : Fakultas Kedokteran Dan Ilmu Keperawatan Universitas Islam Negeri Syarif Hidayatullah.

Fehring, Richard., Schreider, Mery., Raviele, Kathleen. 2006. Variability in the Phases of The Menstrual Cycle. Journal of Obstetric, Gynecologic, and Neonatal Nursing. 35(3). 376384.

Hidayah, N., Rusnoto., Fatma, I. 2017. Pengaruh Abdominal Stretching Exercise terhadap Penurunan Dismenorhea pada Siswi Remaja di Madrasahaliyah Hasyim Asy'ari Bangsri Kabupaten Jepara. Skripsi Diterbitkan. Yogyakarta: Jurusan Keperawa- tan Sekolah Tinggi Ilmu Kesehatan Muhammadiyah Kudus. 954-963.

Huda, M.Pd.I. 2013. Pertumbuhan Fisik dan Intelek Usia Remaja. Al-Ulum. 2(2). 1-15.

Ibitoye, Mobolaji., Choi, Cecilia., Tai1, Hina., Lee, Grace., Sommer, Marni. 2017. Early Menarche: A Systematic Review Of Its Effect on Sexual and Reproductive Health in Low- And Middle-Income Countries. Early Menarche and Sexual and Reproductive Health Systematic Review. 12(6). $1-24$.

Ikalor, A. 2013. Pertumbuhan dan Perkembangan. Jurnal Pertumbuhan dan Perkembangan. 7(1). 1-5.

Khodakarami, Batool., Masoumi, Seyedeh Zahra., Faradmal Javad., Nazari, Mojgan., Saadati, Maryam., Sharifi, Fatemeh., Shakhbabei, Maryam. 2015. The Severity of Dysmenorrhea and Its Relationship With Mass Index Among Female Adolescent In Hamadan, Iran. Journal of Midwifery And Reproductive Health. 3(4). 444-450.

Kusuma, Ilma Anindya., Sirajuddin, Saifuddin., Jafar, Nurhaedar 2015. Gambaran

Pola Makan dan Status Gizi Mahasiswa Program Studi Ilmu Gizi Fakultas

Kesehatan Masyarakat Universitas Hasanuddin Makassar. Skripsi Diterbitkan. Makasar: Fakultas Kesehatan Masyarakat Universitas Hassanudin Makasar. 1-16.

Laila, Annisa Fasichatul. 2016. Hubungan Kelebihan Berat Badan dengan Dysmenorrhea pada Siswi SMK Ibu Kartini Semarang. Skripsi Diterbitkan. Semarang: Fakultas Kedokteran 
Pendidikan Dokter Universitas $\mathrm{Mu}-$ hammadiyah Semarang.

Larasati, Ta., Alatas, F. 2016. Dismenore Primer dan Faktor Risiko Dismenore Primer pada Remaja. Jurnal Majority. 5(3). 79-84.

Mahvash, N., Eidy, A., Mehdi, K., Zahra, M.T., Mani, M., And Shahla. 2012. The Effect of Physical Activity on Primary Dysmenorrhea of Female University Students. World Applied Sciences Journal. 17(10). 1246-1252.

Manurung, Melda Friska., Utami, Sri., Rahmalia, Siti HD 2015. Efektivitas Yoga

terhadap Nyeri Dismenore pada Remaja. Jurnal Online Mahasiswa

(JOM). 2(2). 1258-1265.

Martha, T.B. 2009. Perbedaan Kejadian Dymenorhea Primer antara Wanita Perokok (Aktif dan Pasif) dengan Wanita Bukan Perokok. Skripsi Diterbitkan. Surakarta: Fakultas Kedokteran Universitas Sebelas Maret.

Masen, Tolga B., MD., L.Young, MD,Phd. 2015. Progesterone and The Luteal Phases : A Requisite to Reproduction. HHS Public Access Author Manuscript. 4(1). 135-151.

Meliala, H.D. 2016. Hubungan Pengetahuan Remaja Putri tentang Kesehatan Reproduksi Remaja dengan Kesiapan Menghadapi Masa Pubertas di Desa Pertumbuken Kecamatan Barusjahe Kabupaten Karo Tahun 2015. Skripsi Diterbitkan. Jurnal Wahana Inovasi. 5(2). 459465.

Miko, Ampera \& Dina, Putri Bela. 2016. Hubungan Pola Makan Pagi dengan
Status Gizi pada Mahasiswi Poltekkes Kemenkes Aceh. Journal Action (Aceh Nutrition Journal). 1(2). 83-87.

Mohammed, Reda., \& Khalefa, Tawheda Mohamed El-saidy. 2016. Effect of Home Based Stretching Exercises and Menstrual Care on Primary

Dysmenorrhea and Premenstrual Symptoms Among Adolescent Girls. Iosr Journal of Nursing And Health Science. 5(2). 10-17.

Mtwali, Grace., Pian, Manuel., Angle, Marcia., Murphy, Catherine. 1997. The Menstrual Cycle and Its Relations to Contraceptive Method a Reference for Reproductive Intrah. Columbia: INTRAH School of Medicine University of North Carolina at Chapel Hill 208 N.

Mufadiah. 2012. Hubungan Tingkat Stres Dengan Gangguan Siklus Menstruasi Pada Mahasiswi Diploma IV Bidan Pendidik Tingkat Akhir di Universitas Aisyiyah Yogyakarta. Skripsi Diterbitkan. Yogyakarta: Fakultas Ilmu Kesehatan Universitas 'Aisyiyah Yogyakarta.

Mukherjee, Momin. 2017. A Review Research Design. International Journal Engineering and Management. 2(3). 56-59.

Nasution, S.R. 2012. Pengaruh Pengetahuan tentang Kesehatan Reproduksi

Remaja terhadap Perilaku Seksual Pranikah Remaja di Indonesia. Jurnal Widyariset. 15(1). 75-84.

Niswah, Mustathi'atun. 2016. Hubungan antara Pola Makan Sehari-hari dan

Gaya Hidup Sehat dengan Prestasi Belajar Mahasiswa Pendidikan Biologi Uin Walisongo Semarang. Skripsi Diter- 
bitkan. Semarang: Fakultas Sains dan Teknologi Universitas Islam Negeri Walisongo Semarang.

Paithankar, Dr.S.M., Hande, Dr.D. 2016. Effectiveness of Pilates Over

Conventional Physiotherapeutic Treatment in Females With Primary Dysmenorrhea. IOSR Journal of Dental and Medical Sciences (IOSRJDMS). 15(4). 156-163.

Palar, M.C., Wongkar, D., Ticoalu, S.H.R. 2015. Manfaat Latihan Olahraga Aerobik terhadap Kebugaran Fisik Manusia. Jurnal E-Biomedik (Ebm). 3(1). 316-321.

Pratiwi, H., Rodani. 2015. Obesitas sebagai Resiko Pemberat Dismenore pada Remaja. Jurnal Majority. 4(9). 93-97.

Price, Flona. 2006. What We Know About Primary Dysmenorrhea Today: A Critical Review. Journal Human Reproduction Update. 1(1). 11-20.

Puspitasari, R.L. Elfidasari, D., Rahayu, K.M. 2014. Pengetahuan Mahasiswi

Universitas Al-Azhar Indonesia terhadap Premenstrual Syndrome. Jurnal AlAzhar Indonesia Seri Sains dan Teknologi. 2(3). 193-198.

Putri, Rofi 'Atul Laily Dwi., Melaniani, Soenarnatalina. 2013. Analisis Faktor Hubungan Usia Menarche Dini. Jurnal Biometrika dan Kependudukan. 2(1). 42-50.

Rahayu, M.A., Suryani, L., Marlina, R. 2014. "Efektifitas Senam Dismenore Dalam Mengurangi Dismenore pada Mahasiswa Program Studi D3 Kebidanan Karawang Tahun 2013". Jurnal Ilmiah Solusi. 1(2). 56-61.
Richard, Marisa. 2014. Dysmenorrhea and Body Mass Index. Submitted to the: School of Health Sciences Eastern Michigan University in Partial Fulfillment of The Requirements. 1-32.

Rochmania, B.K. 2015. Sikap Remaja Putri Dalam Menghadapi Perubahan Fisik Masa Pubertas. Jurnal Promkes. 3(2). 206-217.

Rosyida., Suwandono., Ariyanti., Suhartono., Mashoedi., Fatmasari. 2017. Comparison of Effect of Abdominal Stretching Exercise and Cold Compress Therapy on Menstrual Pain Intensity In Teenage Girls. Belitung Nursing Journal. 3(3). 221-228.

Salbiah. 2014. Penurunan Tingkat Nyeri Saat Menstruasi Melalui Latihan Abdominal Stretching Exercise. Jurnal Ilmu Keperawatan. 72-82.

Saleh, Hend S., Mowafy, Hala E., Hemeid, Azza A Abd El. 2016. Stretching or Core Strengthening Exercise for Managing Primary Dysmenorrhea. Journal Of Woman's Health Care. 5(1). 1-6.

Sari, Ratna Yunita. 2017. The Effectiveness of Abdominal Stretching Exercise on Menstrual Pain Level In Students of Semester 8 Prodi S1 Nursing University $\mathrm{Nu}$ Surabaya. Proceeding of Surabaya International Health Conference. 219-223.

Saufika, Rizky Fatria. 2018. Perbedaan Pengaruh Cat Stretching dan Lower Trunk Rotation terhadap Dysmenorrhoea Primer pada Mahasiswi Universitas Aisyiyah Yogyakarta. Skripsi Diterbitkan. Yogyakarta: Fakultas Ilmu Kesehatan Universitas 'Aisyiyah Yogyakarta. 
Shah, Salvi., et all. 2016. Effect of Exercise on Primary Dysmenorrheoea In Young Females. International Journal Pyshyoteraphy And Research. 4(5). 1658-1662.

Sifra, T.A., Kaeng, J., Tendean, H.M. 2013. Hubungan Malnutrisi Dengan Gangguan Siklus Menstruasi di Kawasan Tempat Pembuangan Akhir (TPA) Sumompo. Jurnal e-Biomedic (eBm). 5(1). 1-6.

Sinaga, E., Saribanon, N., Sa'adah, S.N., Salamah, U., Murti, Y.A., Trisnamiati, A., Lorita, S. 2017. Manajemen Kesehatan Menstruasi. Universitas Nasional IWWASH Global One.

Sitoayu., Pertiwi., Mulyani. 2017. Kecukupan Zat Gizi Makro, Status Gizi, Stres, dan Siklus Menstruasi pada Remaja. Jurnal Gizi Klinik Indonesia. 13(3). 121-128.

Sivadasan, Shalini., Ali, Abdul Nazer., Marimuthu, Kasi., Nazer, Zulfikar Ahmed., Chigurupati, Sridevi., Veerasamy, Revichandran. 2014. Menstrual Disorder Among StuduentAn Averview. Journal Research J.Pharm And Tech. 7(6). 704-711.

Sugani. 2014. Pengaruh Endorphine Terhadap Rasa Sakit Dismenore Pada Mahasiswi Jurusan Kebidanan Poltekkes Kemenkes Tasikmalaya. Jurnal Bidan (Midwife Journal). 3(2). 28-36.

Sugihantono. 2014. Gambaran Pola Makan dan Status Gizi Mahasiswa Program Studi Ilmu Gizi Fakultas Kesehatan Masyarakat Universitas Hasanuddin Makassar. Jurnal Kesehatan Masyarakat. 11(1). 25-35.
Sugiharto. 2012. Fisioneurohormonal pada Stresor Olahraga. Jurnal Sains Psikologi. 2(2). 54-66.

Supriyadi \& Wardani, Hartati Eko. 2012. Anatomi Manusia. Malang: Penerbit Universitas Negeri Malang (UM Press). 1-126.

Tuduho, S., Kundre, R., Malara, R. 2014. Hubungan Stres Psikologis dengan Siklus Menstruasi pada Siswi Kelas 1 di SMAN 3 Kepulauan Tidore. Jurnal e-Biomedic. 5(2). 1-7.

Unsal, A., Ayranci, U., Tozun, M., Arslan, G., Calik, E. 2010. Prevelence of Dysmenorrhea and Its Effect On Quality of Life Among a Group of Femele University Students. Upsala Journal of Medical Sciences. 1(2). 138-145.

Utari, N. 2016. Hubungan antara Status Gizi dengan Kejadian Dismenore pada Mahasiswi yang Sedang Mengerjakan Skripsi di Universitas Muhammadiyah Surakarta. Publikasi Ilmiah. Surakarta : Fakultas Ilmu Kesehatan Universitas Muhammadiyah Surakarta.

Vaziri, Farideh., Hoseini, Azam., Kamali, Farahnaz., Hadianfard, Mohamadjavad., Abdali, Khadijeh., Sayadi, Mehrab. 2014. Comparing the Effects of Aerobic and Stretching Exercises on the Intensity of Primary Dysmenorrhea In The Students of Universities of Bushehr. Journal of Family and Reproductive Health. 9(1). 23-28.

Wardhani, D.T. 2012. Perkembangan dan Seksualitas Remaja. Jurnal Kesehatan Masyarakat. 17(3). 184-191.

Wati, L.R., Ariffiandi, M.D., Prastiwi, F. 2017. Hubungan Aktivitas Fisik 
dengan Derajat Dysmenorrhoea Primer pada Remaja. Journal of Issue In Midwifery. 1(2). 1-18.

Watson, Nathaniel., Bliwise, Moderator Donald., Buxton, Orfeu., Buysse, Daniel., Grandner, Michael., Kushida, Clete., Malhotra, Raman., Martin, Jennifer., Patel, Sanjay., Quan, Stuart., Tasali, Esra. 2015. Recommended Amount of Sleep for a Healthy Adult : a Joint Consensus Statement of the American Academy of Sleep Medicine and Sleep Research Society. Journal of Clinical Sleep Medicine. 11(6). 591-592.

Widiyanti, Devi Eka. 2013. Penelitian Pengaruh Nyeri Haid (Dysmenorrhoea) terhadap Aktivitas Sehari-Hari pada Remaja di SMPN 2 Ponorogo. Ponorogo: Fakultas Ilmu Kesehatan Universitas Muhammadiyah Ponorogo.

Wijaya, I.M.K., Agustini, N.Y.M., Tisna, Ms.G.D. 2014. Pengetahuan, Sikap dan Aktivitas Remaja SMA Dalam Kesehatan Reproduksi di Kecamatan Buleleng. Jurnal Kesehatan Masyarakat. 10(1). 33-42.

Wikipedia The Free Encyclopedia. 2014. Menstrual Cycle. Https://En.Wikipedia.Org/Wiki/Mens trual_Cycle. 1-8

Windastiwi, W., Pujiastuti, W., Mundarti. 2017. Pengaruh Abdominal Stretcing Exercise terhadap Intensitas Nyeri Dismenorea. Jurnal Kebidanan. 6(12). 17-26.

Yassin, shadia A.T. 2012. Herbal Remedy Used By Rural Adolescent. Journal of American Science. 8(1). 467-474.
Yuliana, I. 2013. Pengaruh Abdominal Stretching Exercise terhadap Dysmenorrhea Primer Siswi MAN 1 Surakarta. Naskah Publikasi. Surakarta: Fakultas Ilmu Kesehatan Universitas Muhammadiyah Surakarta. 